\title{
¿ES NECESARIO UN GIRO ARETAICO DE LA TEORÍA DE LA ARGUMENTACIÓN JURÍDICA?*
}

\author{
Tasia Aránguez Sánchez \\ Universidad de Granada \\ tasia@ugr.es
}

RESUMEN. La actual teoría de la argumentación jurídica tiene como base epistemológica la ética discursiva de HABERMAS y, en última instancia, la noción kantiana de la racionalidad práctica. Dicho paradigma se basa en una razón fría, que aspira a ser neutral, imparcial, universal y descontextualizada. Este enfoque abandona cuestiones centrales para la argumentación, tales como el carácter de la persona oradora, las emociones del auditorio o la persuasión producida por los elementos estéticos. Por eso, frente al paradigma habermasiano, las llamadas «éticas de la virtud» podrían dar lugar a un nuevo punto de vista de la teoría de la argumentación que se preocupe por los auditorios reales desde una noción de la racionalidad más humana, hermanada con la emoción y la biografía.

Palabras clave: HABERMAS, ética discursiva, ética de la virtud, retórica de la virtud, argumentación jurídica, teoría estándar, dialéctica.

\section{Is it Necessary an «Aretaic Turn» in the Theory of Legal Argumentation?}

ABSTRACT. The epistemological basis of the current theory of legal argument is the discursive ethics of HABERMAS and, ultimately, the Kantian notion of practical rationality. This paradigm is based on a cold reason, which aspires to be neutral, impartial, universal and decontextualized. This approach leaves issues that are central to the argument theory, such as the character of the speaker person, the emotions of the audience or persuasion produced by the aesthetic elements. So, against the Habermasian paradigm, "virtue ethics» could lead to a new point of view of the theory of argumentation that cares about the actual audiences from a notion of the human rationality, coupled with emotion and biography.

Keywords: HABERMAS, discursive ethics, virtue ethics, rhetoric of virtue, legal arguments, standard theory, dialectic.

\footnotetext{
* Fecha de recepción: 4 de agosto de 2016. Fecha de aceptación: 16 de febrero de 2017.
} 


\section{INTRODUCCIÓN}

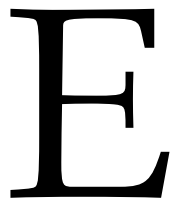

xiste una idea muy extendida de que para el punto de vista retórico una buena argumentación es aquella que logra persuadir, de modo que las reglas que rigen la retórica tienen un carácter puramente técnico: son los medios e instrumentos que pueden usarse para lograr la persuasión. Pero este punto de vista suscita serias dudas con respecto a la legitimidad de la retórica: ¿Qué ocurre si esas técnicas persuasivas se utilizan para fines injustos?, ¿un fin legítimo justifica medios como el engaño? Ante estos problemas, la llamada «teoría estándar de la argumentación» recurre al que podemos denominar «criterio de Perelman» (C. Perelman y L. Olbrechts-Tyteca, 1989: 72): lo importante no es si se persuade o no a un auditorio particular en un momento dado, sino más bien si se logra realizar una argumentación racional, que es la que sería capaz de persuadir a un auditorio ideal formado por personas racionales. Esta tesis de PERELMAN tiene una gran semejanza con la contraposición de HABERMAS (J. HABERMAS, 1981: 143) entre consenso fáctico y consenso ideal.

La teoría de la argumentación actual, cuyo corpus teórico fundamental es denominado «teoría estándar» ${ }^{1}$, aspira a un acercamiento entre la disciplina retórica y la argumentación dialéctica. En el ámbito de lengua hispana tanto VEGA REÑÓN (L. VEGA, 2003) como ATIENZA (M. AtiENZA, 2013: 365) expresan este desiderátum. En el caso de VEGA REÑÓN, la propuesta consiste en el surgimiento de una teoría integradora que reivindique lo mejor de las tres grandes perspectivas de la teoría de la argumentación (lógica, dialéctica y retórica). En el caso de ATIENZA, su propuesta consiste en unificar la dialéctica y a la retórica en la «dimensión pragmática» de la argumentación. Esta fusión podría tener la ventaja de aportar a la retórica la oportunidad de parecerse a la dialéctica, volviéndose más ética y más racional. La retórica devendría una «retórica buena», que intenta convencer a las personas juzgadoras mediante argumentos, y que dejaría de lado sus aspectos de «retórica mala», que es la que intenta persuadir mediante pasiones, imágenes o falacias.

Este desiderátum se corresponde con la preferencia que ARISTÓTELES manifestó por el logos, frente al ethos y al pathos. Como es sabido, ARISTÓTEles (ARISTÓTELES, 1990: RETS II-1357a 31-32) distinguió tres vías distintas de persuasión que forman parte del saber retórico: la que se basa en el carácter de la persona oradora (ethos), la que se basa en las emociones (pathos) y la que se basa en los aspectos internos del discurso (logos). Considero que la «teoría estándar» está intentando limpiar el nombre de la retórica de modo parecido al que empleó ARISTÓTELES; es decir, separando la retórica legítima de la ilegítima, y vinculando a esta última con la manipulación

1 Como señala ATIEnZA la llamada «teoría estándar» surgió como rechazo a entender el razonamiento jurídico en términos estrictamente lógico-formales. Los predecesores de la teoría estándar de la argumentación jurídica se opusieron a la reducción de la misma al razonamiento deductivo. Así, RECASÉNS SICHES defendió la idea del logos de lo razonable frente al logos de lo racional. VIEHWEG sostuvo que lo peculiar del razonamiento jurídico se encuentra en la noción tradicional de tópica, que no se refiere a las estructuras internas de los argumentos, sino a las nociones comúnmente aceptadas y consideradas razonables por parte de la comunidad. PERELMAN, por su parte, siguiendo a ARISTÓTELES, contrapuso los argumentos lógicos a los retóricos, estos últimos no buscarían establecer verdades evidentes, pruebas demostrativas, sino mostrar el carácter razonable de una determinada decisión. M. ATIEnZA, Curso de argumentación jurídica, Madrid: Trotta, 2013, 31. 
propagandística. ARISTÓTELES intentó trazar puentes entre la retórica legítima y la lógica, para dar a la retórica un barniz de credibilidad. La teoría estándar no apela ya a la lógica (de hecho la «teoría estándar» surgió frente a la hegemonía de la lógica formal en la teoría de la argumentación) ${ }^{2,3}$. La teoría estándar trata de purificar la retórica aproximándola a la ética discursiva (dialéctica) de autores como HABERMAS y ALEXY. He de aclarar que esto no es una mera especulación mía, sino que como señala AtienZa (M. AtienZA, 1991: 33), los tres enfoques de la «teoría estándar», a pesar de sus diferencias, comparten aspectos filosóficos comunes tales como la apuesta por una ética discursiva de raigambre kantiana y la preocupación de cuño aristotélico por la estructura de los argumentos.

En el presente trabajo voy a explicitar y criticar los fundamentos de la «teoría estándar» basados en las «éticas discursivas» y, al final de este artículo, voy a esbozar un modelo retórico alternativo, procedente de QuINTILIANO y compatible con las llamadas «éticas de la virtud» (por eso hablo de giro «aretaico») ${ }^{4}$. La razón por la cual considero necesario este cambio de paradigma es que las bases filosóficas de la teoría de la argumentación actual han provocado que la teoría estándar desconfíe y deje en la periferia analítica aspectos centrales como las emociones, el carácter del orador o de la oradora, el humor, la expresión no verbal, la arquitectura del edificio en el que se produce la comunicación y el estilo de los escritos. Mi tesis es que es posible construir una teoría de la retórica jurídica que incluya, sin recluirlos en la periferia, todos estos aspectos, y que dicha teoría puede basarse en una concepción ética. Reivindico esos aspectos a los que la «teoría estándar» mira con recelo. Aunque en este trabajo voy a

2 PeRElman sostiene que no hay que confundir la lógica con la lógica formal, pues ello implica tratar de reconducir los razonamientos habituales de las y los juristas a estructuras formales. El razonamiento jurídico tiene una lógica específica. Su tipo de razonamiento se centra en identificar semejanzas y diferencias, utilizando contraposiciones y analogías. No se trata de llegar a juicios verdaderos, sino a juicios razonables y justos. A diferencia del razonamiento deductivo, en el derecho no podemos hablar casi nunca de algo correcto o incorrecto de una manera impersonal.

Además de oponerse al lenguaje formal, PERELMAN niega la utilidad de la deducción, dado que las deducciones se basan sobre premisas, y en el Derecho lo dudoso son precisamente las premisas. PERELMAN trae la afirmación de S. MiLl de que nadie admitirá la tesis de que todos los hombres son mortales, si duda de que SÓCRATES es mortal, por tanto la conclusión de que SóCRATES es mortal le resultaría una petición de principio. Para convencer al auditorio la oradora o el orador tiene que conocerlo un poco y así sabrá qué tesis pueden tomarse como punto de partida de los razonamientos. Pero incluso aceptando los mismos valores y hechos como punto de partida, hay tal arsenal de estos que es posible llegar a conclusiones muy distintas e incluso opuestas. En el Derecho se producen confrontaciones entre pruebas y entre valores, de modo que la persona juzgadora debe ponderarlos y motivar una decisión. C. PERELMAn, La lógica jurídica y la nueva retórica, Madrid: Civitas, $1979,19,154$ y 176.

3 A pesar de esta tesis de Perelman y de la oposición a la deducción que manifestaron los pioneros de la teoría estándar, la mayoría de los autores que integran la concepción estándar no sostienen que el razonamiento jurídico se oponga a la deducción, sino que para comprender el razonamiento jurídico hemos de contar con más herramientas además de la lógica. Tendrían este punto de vista autores como PECZENIK, AARNIO, AlEXY o MACCORMiCK. Algo característico de este enfoque es la distinción entre la justificación interna (lógica-deductiva, paso de las premisas a la conclusión) y la justificación externa, que se refiere al establecimiento de las premisas y que requiere algo más que lógica deductiva. M. ATIENZA, op. cit., 2013, 31.

4 De «Areté», en griego «virtud» o «excelencia». Las éticas de la virtud que han inspirado este artículo son las de MACINTYRE, NuSSBAum y GADAMER; y la teoría aristotélica que los tres toman como punto de partida. H. Gadamer, Verdad y método (A. Y. Agud, Trans.), Salamanca: Sígueme, 1997. A. Macintyre, Tras la virtud, Barcelona: Austral, 2013. M. NussBAuM, Justicia poética (C. GARDINI, Trans.), Barcelona: Editorial Andrés Bello, 1995. M. Nussbaum, La fragilidad del bien, Madrid: Machado, 2004. Aristóteles, Ética a Nicómaco (M. Araujo y J. Marías, Trans.), Madrid: Instituto de Estudios Políticos, 1970. 
centrarme en las bases teóricas y no en el análisis de dichos elementos, la teoría que esbozaré al final de este artículo tiene la ventaja de que permite situar en el centro a todos esos elementos que tanto influyen sobre la persuasión real, sin caer por ello en la defensa de una retórica propagandística, carente de una base ética y preocupada únicamente por la persuasión.

La perspectiva propuesta en este artículo se integra dentro del resurgimiento, a partir de los años cincuenta, de las éticas de la virtud (giro aretaico) y, en concreto, el presente trabajo se enmarca en el incipiente corpus teórico denominado «jurisprudencia de la virtud» ${ }^{5}$, que está ganando especial relevancia en el ámbito de la argumentación jurídica ${ }^{6}$. Considero que incorporo relevantes elementos originales a esta innovadora corriente, dado que mis reflexiones parten de fuentes distintas a las que inspiran la mayoría de los estudios de la jurisprudencia de la virtud ${ }^{7}$. Parto del estudio de la retórica clásica y, en particular, de la obra de QuinTILIANO. Son esas fuentes las que me condujeron al cuestionamiento de la teoría estándar de la argumentación. Mi mirada se dirige hacia un tiempo en el que la abogacía era considerada la más elevada de las profesiones, que aunaba un conjunto de virtudes morales, intelectuales y cívicas que representaban el ideal de vida de una concepción del mundo a la que se puede denominar «cultura de la retórica». A través de la indagación en la retórica clásica he tratado de trasladar a la teoría de la argumentación aquel espíritu apasionado, de gran potencial humanista y democratizador.

\section{CRÍTICA AL PUNTO DE VISTA DIALÉCTICO DE LA TEORÍA ESTÁNDAR}

Perelman (C. Perelman, 1979) explica que la dialéctica es la dimensión de la argumentación que entra en juego cuando hay una diferencia de opinión que no puede resolverse mediante medición o demostración empírica, o cuando el objeto de debate no es la verdad, sino el valor de una decisión justa, razonable, oportuna o ética. En estos casos la solución más razonable será la que surja de un acuerdo. VEGA REÑón (L. VEGA, 2003) expone las características de la perspectiva dialéctica, que constituye el enfoque central de la teoría estándar, pues ocupa el lugar medio e irradia a las otras dos perspectivas (lógica y retórica). Para este punto de vista de la argumentación, sostiene, todo gira en torno a la existencia de una discusión. La discusión puede producirse en el marco de una deliberación, un debate o una negociación. En cada caso, las reglas serán distintas. Obviamente, no son iguales las reglas que rigen una negociación

5 Algunos trabajos que dan muestra de la jurisprudencia de la virtud son: A. AmAYA y H. HOCK LAI (eds.), Law, Virtue and Justice, Oxford: Hart Publishing, 2012. C. Farrelly y L. Solum, Virtue Jurisprudence, Basingstoke: Palgrave MacMillan, 2008. J. ChapMAn y W. GaLsTON, Virtue, NOMOS XXXIV, New York: New York University Press, 1992.

6 Algunos trabajos que ejemplifican la teoría aretaica de la argumentación son los siguientes: A. AmALIA, «Virtud y razón en el Derecho. Hacia una teoría neo-aristotélica de la argumentación jurídica», en R. GONZÁlez de la Vega y G. LaRiguet, Problemas de Filosofía del Derecho. Nuevas Perspectivas, Bogotá: Temis, 2013. J. SAlDAÑA, Ética judicial. Virtudes del juzgador, México: Suprema Corte de Justicia de la Nación, 2007. E. YANKAH, «Virtue's Domain», University of Illinois Law Review, 2009, vol. 2009, núm. 4.

7 Es sabido que el renacimiento presente de las éticas de la virtud tiene su origen en la relectura de ARISTÓTELES, y lo mismo ocurre con las jurisprudencias de la virtud. 
entre dos abogadas, que las reglas que seguirán estas mismas en su controversia ante los tribunales.

Aquí lo que importa no es si un argumento es bueno desde el punto de vista lógico, sino si la argumentación es adecuada a los fines y a las reglas del tipo de discusión en cuestión. La fuerza de un argumento se medirá, no en abstracto, sino frente a la fuerza de otro que se le oponga ${ }^{8}$, su mayor o menor aceptabilidad ${ }^{9}$, y también se medirá su fuerza en atención a su productividad para el curso del debate, es decir, en atención a si los argumentos promueven nuevos y mejores argumentos, si abren nuevos contextos o trazan nuevas líneas argumentativas. En opinión de VEGA REÑÓN ${ }^{10}$ (L. VEGA, 2003: 131), la perspectiva dialéctica, más que juzgar la estructura interna de un argumento, se plantea si ese argumento es adecuado a las reglas de la discusión. Lo que importa no es un argumento concreto, sino la actitud de argumentar correctamente, siguiendo unas normas que regulan la buena conducta argumentativa. La idea de fondo es la de que, cuando no es posible alcanzar certezas hay que tratar de llegar a un acuerdo sobre cuál es la solución más razonable, y para poder llegar a un acuerdo hay que debatir siguiendo unas reglas que permitan que se produzca un intercambio racional de argumentos, y no un intercambio de amenazas o chantajes.

VAn Eemeren y Grootendorst (F. van Eemeren y R. Grootendorst, 2004: 1) proponen unas reglas para que se desarrolle correctamente la argumentación que ellos denominan «pragma-dialéctica». Las reglas regulan aspectos de sentido común como argumentar la propia tesis o escuchar a las demás personas. En esencia, el principio central de sus reglas es el principio cooperativo: la disposición de las partes a cooperar para alcanzar la mejor solución posible. R. AlEXY (R. AleXY, 1989: 70) también ha formulado un código de reglas, muy parecidas a las de VAN EEMEREN y GROOTENDORST, que también pretenden dar lugar a un diálogo racional, en este caso en el ámbito del derecho.

Se ha objetado a la perspectiva dialéctica que en el derecho las partes no siempre quieren llegar a un acuerdo, y que cuando lo desean, no persiguen el bien común,

${ }^{8}$ La fuerza de las argumentaciones se basa, en gran medida, en la plausibilidad. Las cosas plausibles son aquellas que todo el mundo comparte, las que sostiene la mayoría o aquellas que comparten unas pocas personas pero que son dignas de crédito. La tradición tópica ha mostrado esta conexión entre la dialéctica y la plausibilidad. La analogía y la correlación se basan en la plausibilidad: si consideramos que algo es verdadero, también parecerá verdadero algo muy semejante. La plausibilidad no es un atributo interno de la argumentación, sino que está basada en lo que la gente cree, en lo que tiene respaldo social. Por tanto, es algo graduable, hay cosas más plausibles y otras menos plausibles, de modo que ha de valorarse comparando las opiniones enfrentadas para ver cuál es más plausible.

9 Aunque el presente trabajo no verse sobre el método tópico, considero de utilidad señalar brevemente sus características esenciales. La tópica, señala VIEHWEG, fue conceptualizada por ARISTÓTELES, es un modo de razonamiento consistente en partir de «topoi», puntos de vista utilizables y aceptables universalmente, que se emplean para apoyar la argumentación y que parecen conducir a la verdad. En el diálogo la tópica adquiere gran relevancia pues es necesario alcanzar el común entendimiento y los tópicos pueden facilitarlo. Estos puntos (tópicos) no son aceptados por mera autoridad, sino que entre personas cultas se acepta como razonable lo que tiene determinado peso, como es el caso de los juristas de reconocido prestigio. Depositar confianza en ellos no constituye una mera creencia. T. VIEHWEG, Tópica y jurisprudencia, Madrid: Taurus, 1964.

${ }_{10}$ En este artículo expongo las tesis más canónicas de VEGA REÑón, pero he de señalar que dicho autor se está alejando progresivamente del trasfondo de las tesis racionalistas que subyacen a la ética discursiva. Esto puede observarse en L. VEGA, Introducción a la teoría de la argumentación: Problemas y perspectivas, Lima: Palestra Editores, 2015. 
ni buscan la verdad, sino que persiguen sus propios fines o intereses que casi nunca serán compatibles con las reglas basadas en el principio cooperativo. ALEXY y VEGA REÑÓN defienden la perspectiva dialéctica argumentando que, incluso en el contexto más estratégico (pensemos en una negociación jurídica) es necesario que exista un mínimo de buena fe argumentativa. VEGA REÑÓN (L. VEGA, 2003: 289) pone un ejemplo clarificador de esta tesis: la comunicación se parece al comercio en el sentido de que nadie podría comprar ni vender si no existiera el principio de la buena fe mercantil, que parte de que los demás van a cumplir sus compromisos. Nadie podría argumentar si todas las personas presumieran que las demás mienten por sistema. Es necesario que exista un mínimo de sinceridad, un mínimo de confianza y un mínimo de buena fe para que exista un diálogo (o un proceso legal). Considero que los autores tienen razón: de no ser así, todos los asuntos se resolverían mediante la violencia privada dado que nadie confiaría en el derecho.

Este argumento de ALEXY y VEGA REÑÓN fue formulado, aunque de manera más compleja, por HABERMAS (J. HABERMAS, 1981) en su Teoría de la acción comunicativa. Nava Tovar (A. TOVAR, 2015: 242), discípulo de AleXY explica la idea alexyana de la pretensión de corrección que rige en el derecho y que implica que, para que la comunicación sea posible en el ámbito jurídico, es necesario que confiemos en que el derecho tiene la finalidad de servir a la justicia. AlEXY señala que en el derecho, la judicatura y el legislativo forman parte de un discurso oficial que, si no desea ser considerado simple fuerza bruta, debe procurar la aceptabilidad de la sociedad. La pretensión de justicia es, por tanto, un elemento totalmente necesario para la existencia de un sistema jurídico. AlEXY probará esto mediante el ejemplo de las contradicciones performativas ${ }^{11}$. La pretensión de corrección significa que el derecho intenta parecer moralmente correcto, lo que no implica necesariamente que lo sea ${ }^{12}$.

Estas explicaciones permiten comprender por qué la perspectiva dialéctica considera que las reglas del diálogo no son una mera convención, sino la condición de posibilidad de cualquier comunicación lingüística, incluyendo la comunicación que se produce en el ámbito del derecho ${ }^{13}$ (R. AlEXY, 1989: 183). Ahora bien, y aquí formulo una primera crítica al punto de vista dialéctico: aunque comparto que en el derecho existe una pretensión de corrección, considero que la etérea pretensión de corrección no logra demostrar que en el derecho existan o que deban existir las reglas tan específicas que formula ALEXY. No parece posible fundamentar la necesidad de que una abogada sea completamente sincera durante un litigio, por ejemplo. Más bien al contrario, parece que la judicatura es plenamente consciente de que

11 La contradicción performativa es la siguiente: imaginemos un Tribunal Superior que se llamase «Tribunal Supremo de Injusticia de la Nación»; ¿quién respetaría los fallos de semejante tribunal?, se pregunta ALEXY, ¿podría instaurarse un tribunal con semejante nombre sin que la sociedad hiciera algo al respecto? Ningún tribunal apela a la injusticia para dictar sentencias. Incluso aunque la judicatura no creyese en la justicia en su fuero interno, tendría que apelar a ella en términos institucionales. Cfr. R. AlEXY, Teoría de la argumentación jurídica (M. ATIENZA, Trans.), Madrid: Espejo CEC, 1989.

12 Es cierto que un tribunal puede llevar el sustantivo «justicia» en su nombre y dictar fallos injustos, pero eso tan solo confirma la necesidad de la pretensión institucional de justicia, incluso en los regímenes más injustos. Las leyes y fallos deben parecer justos aunque no lo sean, pues de lo contrario no serían considerados «derecho».

13 A esto se le llama «fundamentación pragmatico-transcendental». 
la abogacía por lo general no es, ni completamente mentirosa ni completamente sincera $^{14,15}$.

Sin embargo, mi discrepancia principal con el punto de vista dialéctico no proviene de su tesis de que el derecho sirve a la justicia. La idea con la que discrepo (lo que me conduce a formular una segunda crítica) es la que vincula dicha justicia con el acatamiento de unas reglas que se presentan como algo formal, prácticamente carente de contenido material. Es decir, las reglas se presentan como si estuvieran por encima de las consideraciones éticas particulares y de los puntos de vista en liza de la sociedad. Las reglas son vistas como algo apriorístico. El ideal de VAN EEMEREN y GROOTENDORST (F. VAN EEMEREN y R. GROOTENDORST, 2004: 73) se basa en la idea de que la argumentación debe intentar convencer a una persona razonable. Los autores asumen una noción de racionalidad que privilegia los elementos lingüísticos de la comunicación (frente a los no verbales) y las consideraciones intelectuales (frente a las emociones y las intenciones). Sin embargo, la noción de racionalidad contenida en las reglas propuestas por estos autores no es técnica o neutral, sino que tiene un contenido valorativo. El contenido valorativo recoge principios básicos como la igualdad de derechos, la ausencia de coerción y la búsqueda de la universalidad de las decisiones. Este contenido valorativo se defiende por la dialéctica como el más neutral posible, es decir, el contenido valorativo estrictamente imprescindible para posibilitar un debate racional en el que se pueda alcanzar la mejor solución posible.

Por tanto, considero que la propuesta dialéctica no debería presentarse a sí misma como si fuese algo incuestionable, algo que forma parte de la naturaleza de cualquier acto comunicativo. No debería presentarse como si no hubiera ninguna persona, ninguna ideología y ningunos intereses detrás de la misma. En definitiva, pienso que no debería autoproclamarse (sin humildad intelectual alguna) como «pragmática-transcendental», es decir, como concebida sin madre ni padre, en la fuente misma de la racionalidad. La visión de la racionalidad del punto de vista dialéctico (de raigambre habermasiana) es expresión del racionalismo europeo e ilustrado que privilegia una determinada visión de la verdad, la justicia y la racionalidad. Encontramos en la ética que sustenta a dicha perspectiva una determinada visión de la racionalidad «kantiana» que pretende ser transcendental, formal, desprovista de contenido material y basada

14 Las reglas del discurso racional que establece ALEXY no parecen aplicables fácilmente a los litigios jurídicos (y aún menos a las negociaciones). Su carácter necesario e inherente a todo acto comunicativo es dudoso. En el derecho las normas procesales garantizan cierta ética discursiva, aunque mucho más modesta que la postulada por ALEXY. Otro aspecto que no comparto con AlEXY es su tesis de que el derecho es un tipo de discurso especial que se diferencia de la comunicación general porque en el derecho hay que respetar, ante todo, el precedente y el principio de universalidad. Considero que el precedente representa, en su cara negativa, una dimensión autoritativa del derecho y en su cara positiva, representa un compromiso con el diálogo social y con el valor de la igualdad jurídica. Sin embargo, la deferencia al precedente no debería ser la piedra angular de la actuación judicial, pues esto daría lugar a una jurisprudencia muy conservadora. Considero que el respeto al precedente debe complementarse, en un sistema de enfoque dialéctico como este, con una marcada tendencia judicial hacia la promoción de la justicia y los derechos humanos.

15 WALTON considera que no todas las argumentaciones en el Derecho pueden reducirse a un diálogo racional, y esto puede criticársele a ALEXY. En el Derecho hay otros tipos de diálogos como la negociación, el interrogatorio de búsqueda de información, el diálogo educativo, el debate jurídico, etc. Y, por otra parte, la argumentación jurídica no tiene porqué girar en torno a la idea de consenso, tan propia del punto de vista dialéctico, pues hay otros valores en el Derecho como la justicia o la verdad. D. WALTON, Informal Logic. A Handbook for Critical Argumentation, Cambridge: CUP, 1989. 
en una universalidad de la razón imparcial, incorpórea y sin contexto ni biografía. Esa racionalidad casi divina decide con ayuda de un imperativo categórico de nuevo cuño, que toma forma en las reglas del discurso racional. Esta idea, aplicada al derecho, nos conduciría a una idea de persona juzgadora que se autoproclama «imparcial» y que intenta dejar a un lado sus emociones.

NusSBAum (M. NussBAuM, 2012) ha criticado esta visión kantiana de la racionalidad, que se concibe como algo idealizado y contrapuesto a la animalidad y también a las emociones. La racionalidad kantiana consiste en la capacidad de realizar juicios morales. El agente kantiano reflexiona de manera solitaria, es adulto, con una determinada capacidad intelectual, y no posee necesidades corporales, ni necesita asistencia para desenvolverse. La dignidad humana en KANT radica en la autonomía moral e ignora, por tanto, la naturaleza dependiente de muchos momentos de la existencia humana, así como la ubicación corporal y sociocultural de la razón. El problema de la concepción kantiana es que su concepto de racionalidad se basa en la capacidad de abstraerse de la propia identidad para alcanzar una suerte de mirada universal. El relativismo moral puede acusar a KANT, con razón, de enmascarar sus propias nociones éticas heredadas tras un manto de imparcialidad y objetividad.

Habermas (J. Habermas, 1989), principal exponente de este punto de vista, considera que no todos los juicios morales son iguales, sino que es posible considerar que algunos de ellos son más racionales que otros. Según HABERMAS, el criterio que nos permite diferenciar a los mejores juicios morales es el de que todas las personas con las que yo pudiera entablar un diálogo (incluyendo a todas las personas que han existido y existirán) pudieran estar de acuerdo conmigo. AleXY (R. AleXY, 1989: 120) explica que esta noción de acuerdo es criticable, ya que no se puede conseguir el acuerdo de todas las personas, porque las personas fallecidas no pueden dialogar y no sabemos en qué sentido se hubieran pronunciado. HABERMAS (J. HABERMAS, 1981) intenta salvar estas dificultades considerando que solo puede considerarse racional un consenso ideal basado en el principio de universalidad (o generalizabilidad). Nótense las semejanzas entre la propuesta habermasiana y la kantiana. Imaginar este hipotético consenso racional nos permite alcanzar soluciones éticas que todo el mundo pueda querer. El tipo de normas que todo el mundo pudiera querer es el de las que cumplen la característica de generalizabilidad, es decir, las que satisfagan necesidades que sean aceptables por todas las personas. El consenso racional sería aquel al que llegaríamos mediante la situación ideal de diálogo, en la que no se diesen coacciones que interfieran sobre la comunicación libre e igualitaria ${ }^{16}$.

Desde mi punto de vista, y aquí formulo una tercera crítica al punto de vista dialéctico, la propuesta de HABERMAS es más transcendental que intersubjetiva, en el sentido de que su criterio para elegir un buen juicio ético radica en una determinada noción de la razón (razón imparcial y abstracta) más que en la indagación de los valores compartidos con otras personas.

16 Habermas establece una serie de reglas del buen diálogo: 1. Todos los participantes, por igual, pueden iniciar un discurso, replicar, preguntar y responder. 2. Las opiniones anteriores pueden ser cuestionadas y criticadas. 3. Todos los hablantes pueden expresar sus opiniones, sentimientos e intenciones. 4. Todos los hablantes pueden, por igual, ordenar, oponerse, permitir, prometer, rendir y exigir cuentas. 
La concepción liberal de la persona (que está implícita en la teoría de KANT, de HABERMAS o de RAWLS) según MACInTYRe (A. MACINTYRe, 2013: 314), parte de una persona que se da a sí misma su propia ley. Es su aislamiento lo que le impone la carga de un intenso trabajo de deliberación moral, porque reniega de todo concepto de lo bueno que proceda de su contexto, reniega de las normas sociales y de las virtudes que admira la sociedad en la que vive, así como de los sentimientos compartidos de la comunidad que configuran la comprensión social de lo valioso y lo bueno. Este individuo del liberalismo se arranca a sí mismo del mundo, de la narrativa vital en la que aprendió desde la infancia interiorizando fines y propósitos, de un sentido de la vida al que aspiró con anhelo, desarrollado en el seno de la comunidad. La persona ilustrada se enfrenta a la comunidad social de la que forma parte y, de manera casi heroica, quiere inventar por sí misma la moral, transformándose si es necesario en una razón pura, al despojar a su propia identidad de todo cuanto esté contaminado por la tradición.

Otra tesis problemática del punto de vista dialéctico es la incidencia sobre autores dialécticos como ALEXY que sostienen además que, junto a las reglas comunicativas, es necesario que exista una autoridad que decida si se están siguiendo adecuadamente. Esto, como acertadamente señala VEGA REÑÓN (L. VEGA, 2003: 145), supone abandonar el paradigma intersubjetivo. El derecho, en el modelo dialéctico de ALEXY, como vemos, no es un debate intersubjetivo, sino más bien un debate mediado por un tercero (juez o jueza) que se conduce por el ideal de imparcialidad. Tal imparcialidad se supone que es lo que garantiza que en los litigios prime el intercambio racional de argumentos y que no se trate de una simple negociación de intereses. Me temo, y aquí presento una cuarta crítica al punto de vista dialéctico, que esta tesis de la autoridad imparcial aunada con el aura incorpórea y prístina de la racionalidad dialéctica, acaba legitimando a las instituciones (y en particular a las personas juzgadoras), concibiéndolas como las representantes de la racionalidad discursiva, como las bocas que pronuncian las palabras más cercanas a la verdad a las que se puede acceder en un mundo desencantado.

\section{PERELMAN Y LA NUEVA RETÓRICA}

Hablar del punto de vista retórico de la teoría estándar es hablar, fundamentalmente, de PERELMAN, el padre de la «Nueva Retórica» ${ }^{17}$. LÓPEZ EIRE (A. LÓPEZ EIRE, 1998) explica que esta «Nueva Retórica» se retroalimenta con los principios de la ética del discurso propugnados por HABERMAS. Es decir, el punto de vista retórico adopta, al igual que el punto de vista lógico, las mismas bases filosóficas que el punto de vista

17 Cuenta López EIRE que, junto con la Nueva Retórica de Perelman, que es la propuesta más avalada por la teoría estándar, también hemos de citar al grupo $\mu$ (o grupo de Lieja), que formula la Retórica General. Esta concepción, a diferencia de la de PERELMAN, no se centra en la argumentación sino en el estilo. Concibe la retórica como un instrumento de la poética, acogiéndose a la síntesis aristotélica entre retórica y poética en el área del estilo, y a la tradición humanista del renacimiento que vio en la retórica un arte creativo. La Retórica General se restringe al estilo y por eso se llama «grupo $\mu$ », en alusión a la primera letra de la palabra «metáfora» (metabolés) en griego. Este grupo centra su trabajo en la clasificación de figuras retóricas o literarias. A pesar de la aportación del grupo de Lieja, que es de tipo clasificatorio más que filosófico, la visión dominante del punto de vista retórico en el interior de la «Teoría Estándar» es la de PERELMAN. A. LÓPEZ EIRE, «La retórica clásica y la actualidad de la retórica», en VVAA, QuINTILIANO, Historia y actualidad de la retórica (vol. I, 203-315), Logroño: Instituto de Estudios Riojanos, 1998, 299. 
dialéctico. En efecto, PERELMAN se acerca a la dialéctica porque quiere restaurar la denostada imagen de la retórica. Es decir, PERELMAN intenta hacer lo que en su día hizo ARISTÓTELES: mostrar que la retórica no es una mera técnica para el logro de la persuasión, sino que en ella tiene lugar la ética. PERELMAN defiende que puede existir un marco ético que regule las relaciones entre la persona oradora y su público.

Cuenta LÓPEZ EIRE que ARISTÓTELES intentó, al igual que se intenta en nuestros días, mejorar la imagen denostada de la retórica, y que lo hizo destacando su carácter argumentativo y la proximidad de los argumentos retóricos con los silogismos, inaugurando el terreno de la verosimilitud, a medio camino entre la verdad y la creencia irracional. Lo que trataba de evitar ARISTÓTELES era que todas las cuestiones de la vida, de gran importancia, que no son susceptibles de demostración, quedasen en manos de la irracionalidad. La tesis aristotélica es que la razón tiene cabida en el lugar de la opinión y del consenso social. Pero, objeta LÓPEZ EIRE ${ }^{18}$, por mucho que ARISTÓTELES nos diga que la retórica guarda similitudes con la lógica, nos se nos escapa, ni tampoco al propio ARISTÓTELES, que en la retórica no solo se emplean argumentos que apelan a la sabiduría común, sino que hace gala del noble carácter del orador o la oradora (ethos), del estado de ánimo del auditorio (pathe) y de la emoción placentera que provocan la estética y la belleza de la palabra (estilo). En suma, la retórica es hechicera y cautivadora.

Como explica López Eire, Perelman, fundador de la «Nueva Retórica» se enfrentó también al dilema de si debían dejarse de lado todas las cuestiones no susceptibles de demostración científica. PERELMAN rehabilitó la retórica antigua indagando las relaciones del discurso retórico con el lógico y rebelándose contra la concepción de la retórica como arte de hablar y escribir bien haciendo caso omiso de la argumentación. PERELMAN se enfrentó al rechazo cartesiano a la retórica (pues el cartesianismo solo cree en la verdad científica) y a las retóricas estratégicas de moda; igual que ARISTÓTELES se enfrentó a PLATÓN y a la sofística. El modelo de la «Nueva Retórica» concibe a la retórica, ante todo, como teoría de la argumentación (y no como exaltación de las pasiones, del carácter o de la belleza estilística). La retórica, para PERELMAN es parte de la dialéctica, que se basa en el arte de razonar a partir de opiniones generalmente admitidas ${ }^{19}$.

La dialéctica de PERELMAN está asociada a la lógica informal, en la que no se pretende alcanzar verdades cartesianas, con deducciones que surgen de las premisas por la fuerza de los axiomas, sino que, mediante argumentos parecidos a los de la lógica formal podemos aspirar a mostrar el carácter razonable de una propuesta, sin pretender que esa propuesta sea universal, pues admitimos que caben tesis contrarias ${ }^{20}$. La parte de la tradición retórica que PERELMAN rescata es la que persuade por medio del

18 Ibid., 290.

19 Ibid., 293.

20 Esto que explica tan bien LóPEz EIRE lo dice también claramente el propio PERELMAN. Así, en La lógica jurídica y la nueva retórica, explica que su meta era encontrar una metodología que permitiera realizar razonamientos sobre cuestiones valorativas. Por eso, él y OLBRECHTS-TYTECA analizaron múltiples textos jurídicos tratando de estudiar cómo operaba la lógica en la argumentación jurídica y llegaron a la conclusión de que en el ámbito del derecho no había lógica formal, sino técnicas de argumentación propias de la tradición retórica, dialéctica y tópica, tal y como dicha tradición era concebida antes de que la retórica quedase reducida a una recopilación de recursos literarios. C. PERELMAN, La lógica jurídica y la nueva retórica, Madrid: Civitas, $1979,136$. 
discurso, excluyendo tanto la violencia como la seducción (es decir, excluyendo la parte más estética y emocional de la retórica, y quedándose con la más cercana al logos).

Perelman (C. Perelman, 1979) rescata un concepto relevante en la retórica (el de «auditorio») y lo reforma para dar a la retórica un giro hacia un modelo de ética discursiva muy semejante al habermasiano. Este es el modo que PERELMAN escoge para limpiar a la tradición retórica de impurezas. Como es sabido, ARISTÓTELES estudió los auditorios particulares, que se diferenciaban por la edad y por la posición social de las personas que los integraban. El Estagirita analizó la forma de ser propia de varios grupos de edad (juventud, madurez y vejez) y de distintos estratos socioeconómicos. El aspecto que ARISTÓTELES estudió fue la predisposición de esos grupos a experimentar determinadas emociones ante distintas situaciones (por ejemplo, la propensión de la juventud a apasionarse). Estas variaciones en el carácter de las personas que componen el auditorio condiciona la eficacia del discurso en ese público concreto. Frente a este auditorio de ARISTÓteles, PERELMAN imagina un auditorio universal, formado por cualquier persona razonable. Es decir, PERELMAN se centra en los aspectos discursivos que podrían convencer a cualquier interlocutor posible, sin importar su edad o condición social.

La persona razonable de PERELMAN, a la manera de la dialéctica, nace sin biografía, sin historia y sin emociones. Es incluso incorpórea, de modo que su presencia real no es necesaria. Es solo un artificio imaginativo en la imaginación de la persona orado$\mathrm{ra}$, que le sirve para calificar de eficaz a su propio discurso sin tener que someterse a los antojadizos auditorios formados por gente real. Por tanto, esta «Nueva Retórica», sostiene PERELMAN, nace unida a la dialéctica, e incluso a la lógica formal, que se considera algo complementario y útil para los momentos en los que sean necesarias las demostraciones.

Alexy (R. Alexy, 1989: 142) señala que, para Perelman, la retórica se legitima por remisión a la razonabilidad del auditorio al que persuade. Por eso, en el centro de la teoría de PERELman se encuentra la caracterización de un auditorio al que solo se persuade mediante argumentos racionales. Para PERELMAN este es el auditorio universal, que es el criterio para la racionalidad y objetividad de la argumentación. Sin embargo, ALEXY constata que PERELMAN encuentra algunas dificultades de fundamentación, que son semejantes a las dificultades a las que se enfrentó HABERMAS con su ética discursiva. La primera de ellas es que un acuerdo real de todas las personas es algo imposible. Quien se dirige al auditorio universal sabe que es imposible que todos los seres humanos escuchen sus argumentos, y no espera que el mundo entero concuerde con ellos, pero sí parte de que todas las personas, si tuvieran conocimiento de sus argumentos y los comprendieran, estarían de acuerdo con ellos.

Lo más complicado de la idea de Perelman, afirma Alexy, es su tesis de que la composición de este auditorio universal depende de cómo cada uno de nosotros, desde nuestra cultura y circunstancias, nos imaginamos tal auditorio universal. PERELMAN (C. Perelman, 1957) plantea, siguiendo el imperativo categórico de KANT (I. KanT, 1981), la exigencia de comportarnos como si fuésemos una persona juzgadora cuya decisión deba proporcionar un principio válido para todo el mundo ${ }^{21}$. En consecuencia,

${ }^{21}$ Esta tesis de AlEXY se parece a otra de VEGA REÑÓN. Sostiene dicho autor que podríamos considerar buena argumentadora a la persona que obra de acuerdo con esta máxima de corte kantiano: «Argumenta de 
la persuasión del auditorio universal es la persuasión de todos los seres racionales. El auditorio no es, según PERELMAN, el conjunto de todos los seres humanos reales. El auditorio universal es la humanidad ilustrada, el conjunto de seres humanos en tanto que seres racionales, que poseen información y tienen competencias para comprenderla (R. AlEXY, 1989: 162). El auditorio universal, por tanto, podría entenderse como la totalidad de las personas en el estado en el que se encontrarían si hubieran desarrollado sus capacidades argumentativas.

El auditorio universal de PERELMAn se corresponde con el consenso alcanzado bajo condiciones ideales en la filosofía de HABERMAS. La idea central en el planteamiento de ambos es el principio de universalidad: un juicio de valor solo puede considerarse argumentado si todas las personas racionales pudieran estar de acuerdo. En la «Nueva Retórica», continúa AleXY (R. AleXY, 1989: 165), lo que se busca no es la persuasión de un auditorio real, formado por personas de carne y hueso al que nos estamos dirigiendo en un momento concreto. El concepto de filosofía de PERELMAN no se orienta a persuadir, sino a convencer. No se busca realizar un discurso eficaz, sino un discurso válido, capaz de lograr el asentimiento de todos los seres racionales. Dado lo expuesto hasta aquí, puedo concluir que la perspectiva retórica de la teoría estándar, se encuentra más cerca del punto de vista dialéctico que de la propia tradición retórica.

Según Vega ReÑón, la pregunta ¿qué es una buena argumentación para la retórica? habría de responderse con la respuesta: la que logra persuadir; mientras que la pregunta ¿qué es una buena argumentación para la dialéctica? se respondería: la que cumple con las reglas del diálogo racional ${ }^{22}$. Si aceptásemos esta clasificación de VEGA REÑÓn observamos que con la tesis del auditorio universal de PERELMAN, nos hemos salido del punto de vista retórico y nos hemos adentrado en el dialéctico. La buena argumentación ya no es, como en la tradición retórica, la que consigue persuadir a un auditorio particular, sino que la buena argumentación es la que realizaría una persona racional (entendiendo por «racionalidad» una concepción kantiana como la que adopta HABERMAS).

manera que tus intervenciones discursivas sean contribuciones que respeten los valores de la argumentación y faciliten nuevas contribuciones a los fines de la argumentación en su marco y contexto». Los valores que aporta la buena argumentación son el entendimiento mutuo, el respeto de cada persona a sí misma y a sus interlocutoras como agentes discursivos autónomos y competentes, la asunción de las responsabilidades contraídas y el control efectivo de la información y del conocimiento compartido o público. L. VEGA, op. cit., 2003, 289.

22 Por supuesto, esta clasificación de VEGA REÑón es cuestionable (de hecho, yo la cuestiono dado que mi noción de retórica no se limita a verla como arte de persuasión, pues incorpora una ética), pero por el momento nos sirve a efectos filosóficos. Ahora bien, paradójicamente, otras propuestas históricas que se llaman a sí mismas «dialécticas», pertenecen al punto de vista retórico según la clasificación que tomo de VEGA REÑÓN basada en la pregunta ¿qué es una buena argumentación para el punto de vista retórico?; he señalado que la respuesta a esta pregunta es: aquella que logra persuadir. Pues bien, veamos lo que escribió SCHOPENHAUER en su célebre El arte de tener razón. Explica el filósofo que en la dialéctica hay que dejar de lado la verdad, o considerarla accidental. La dialéctica consiste en el arte de tener razón, en defenderse contra ataques de todo tipo. La dialéctica no se preocupa por quién tiene razón realmente, al igual que en la esgrima no se tiene en cuenta quién tenía razón en la discusión que originó el duelo. La dialéctica es una esgrima intelectual. Como vemos, la dialéctica erística de SCHOPENHAUER alude a una retórica que se despliega en el contexto de un debate, al igual que hicieron otros autores de la tradición retórica, pues dicha tradición siempre se ha preocupado por los debates rápidos y de intervenciones cortas, y no solo por los discursos unilaterales. A. SCHOPENHAUER, El arte de tener razón, expuesto en 38 estratagemas (F. VolPI, Ed., y J. AlborÉs, Trans.), Madrid: Alianza, 2002, 17. 
Pero las similitudes entre la «Nueva Retórica» y el punto de vista dialéctico no quedan aquí. ALEXY señala que, si adoptamos la tesis del auditorio universal estaremos aceptando algunas reglas discursivas implícitas: la persona que se dirige al auditorio universal se dirige también a sí misma, por lo que se excluye la mentira; además ha de ser imparcial, pues quien actúa con parcialidad solo convence a las personas que se encuentran en la misma situación. Perelman (R. AleXY, 1989: 171) sostiene que la persona oradora, cuando se dirige a un auditorio particular, debe apoyarse en lo que las y los oyentes le concedan en un principio. La diferencia es que, cuando se habla a un auditorio universal, la persona oradora trata de proponer tesis que todas las personas racionales puedan compartir.

PERELMAN, en su intento por rechazar la visión de la retórica como «persuasión a cualquier precio», pretende sustituir a la persuasión por un interés más elevado, que tienen aquellas personas que dirigen al auditorio universal: la convicción racional. Esta convicción racional, además, no se basa en la calidad de las inferencias argumentales, ni en su correspondencia con la verdad; sino que se basa en la capacidad de la persona oradora de imaginar a todas las personas racionales, según claro está, su propia noción de racionalidad (vemos cuanto recuerda esta noción de PERELMAN al «imperativo categórico» de KANT). Por tanto, vemos que PERELMAN llama «Nueva Retórica» a una propuesta que encaja perfectamente en la filosofía que adopta el punto de vista dialéctico de la teoría estándar. Realmente ese sustrato filosófico es precisamente lo que caracteriza a la llamada «teoría estándar de la argumentación».

\section{LA RETÓRICA DE LA VIRTUD}

Frente al sustrato filosófico de la «teoría estándar», la cultura romana nos ofrece una fundamentación distinta de la retórica y una original respuesta a la pregunta sobre la legitimidad moral de la retórica. El carácter romano era demasiado práctico para denostar elementos persuasivos como las emociones o la belleza. Por eso CiCERÓN desarrolla un ideal humanista que ilustra un giro hacia lo que podríamos llamar «retórica de la virtud», que constituye un aumento de la importancia de los elementos psicológicos y, especialmente, del ethos de la persona abogada, entendido como configuración de un carácter enriquecido por múltiples virtudes y conocimientos intelectuales y morales.

En el modelo ciceroniano, la legitimidad de la retórica no procede de su analogía con la lógica ni de su tratamiento de lo verosímil (es decir, de una verdad de segunda clase); sino que procede de la dignidad inherente al habla, como cualidad característica y distintiva del ser humano. El habla, unida al cultivo de la sabiduría y orientada hacia la acción en la esfera pública, da lugar a la retórica. La retórica es la fuente de la dignidad humana, pues dice CICERÓN, «aunque en mi opinión los hombres son en muchos aspectos inferiores y más débiles que los animales, los superan especialmente por la capacidad de hablar» (M. CICERÓN, 1997: 91). La retórica es, según CiCERÓN, un elemento definitorio de la actividad política ${ }^{23}$. CICERÓN desarrolla una noción de

23 Ibid., 93. 
retórica que explica bien el significado primigenio de la misma: la retórica expresa el ejercicio de la ciudadanía y el cultivo de las virtudes que permiten alcanzar una vida óptima en el seno de la sociedad. En esta filosofía ciceroniana la sabiduría se pone al servicio de la praxis y es un elemento necesario de la figura del «orador».

Quintiliano (M. Quintiliano, 2001), es el gran sucesor de Cicerón. Para él la retórica es la esencia de la educación humanista, de la persona de letras que además se conduce por un ideal de virtud moral. La retórica de la virtud que defiende QuiNTILIANO bebe del estoicismo romano y también de la retórica de ISÓCRATES (ISOCRATES, 1928) que había defendido el ideal republicano según el cual la retórica era la enseñanza central de la completa educación intelectual y moral que debía poseer cualquier ciudadano de la polis. GORGIAS ${ }^{24}$ también había sostenido que un orador debe comenzar por ser justo, de modo que, contra las acusaciones aristotélicas, la retórica sofística no era una mera técnica, sino que contenía una educación ética.

Siguiendo a LÓPEZ EIRE (A. LÓPEZ EIRE, 1998: 237), según QuiNTILIANO, para ser un orador se debe ser dos cosas: una persona buena y una persona experta en hablar de modo persuasivo. En el modelo de QuINTILIANO, por consiguiente, la retórica consiste en dos cualidades: en ser una persona que se conduce de modo ético y en ser capaz de persuadir mediante la palabra. Este aspecto de la filosofía de QuINTILIANO es central y no debería pasar desapercibido: para QuINTILIANO la retórica no es simplemente el arte de persuadir, sino el arte de persuadir ejercido por una persona que posee una determinada educación moral e intelectual. Es decir, ante la pregunta de VEGA REÑón (L. VEGA, 2003) ¿qué es una buena argumentación según este punto de vista?, QUINTILIANO respondería: la argumentación persuasiva realizada por una persona que ha construido un determinado carácter. No hay oratoria sin persona oradora. No hay retórica sin ethos.

LÓPEZ EIRE explica que el orador de QuiNTILIANO es alguien que ejemplifica el ideal ético e intelectual de su sociedad. La retórica requiere conocimiento de la poesía, la filosofía, la pedagogía, la ética, el derecho, la política, la teoría literaria y la gramática. La retórica es la asignatura fundamental de la formación humana total, provista de marcados perfiles morales. Es una retórica humanista que se estudia en la escuela romana. QUINTILIANO señala, en relación con este cuestión, que existe una diferencia entre opiniones que consiste en que «algunos pretenden que aun los hombres malos pueden llegar a ser oradores; otros, por el contrario (a cuya opinión me arrimo), dicen que el arte de que tratamos no puede convenir sino a los buenos». Y continúa diciendo «los que quitan a la elocuencia aquella principal alabanza de vida, que es la virtud, hacen consistir este arte en la persuasión, o en decir y hablar a propósito para persuadir, lo cual, dicen, lo puede lograr el hombre aunque no sea virtuoso» (M. QuinTILIANO, 2001: $\$ 2-17-1)$.

Sin embargo, opina QuinTILIANO, la persuasión no puede ser sin más el elemento distintivo de la retórica, ya que pueden persuadir el dinero, la autoridad, «la dignidad de la persona, y aun su sola presencia sin hablar palabra, [...] por la memoria de los méritos del sujeto, por verle miserable y aun por prendarnos de su hermosura» ${ }^{25}$. Y

24 Platón, 1983; Gorgias, Diálogos (J. Calonge, Trans.), Madrid: Gredos, $\$ 456$ d-e; 457 a; 460 c-e.

25 Ibid., \$2-16. 
cuenta, a propósito de esto último, la célebre anécdota de la hermosísima Phriné, que ganó un pleito porque se desabrochó la túnica, descubriendo parte de su cuerpo ${ }^{26}$. Por otra parte, QUINTILIANO señala que la definición aristotélica de la retórica, consistente en encontrar argumentos racionales adecuados para persuadir tiene el problema de que no tiene en cuenta aquello que no es argumentación, pero que es vital en la retórica, como el estilo ${ }^{27}$.

QUINTILIANO considera que «la retórica es el arte del bien hablar» ${ }^{28}$, recogiendo la opinión de GORGIAS de que no puede haber un verdadero orador que no se conduzca con justicia. A continuación QuiNTILIANO señala que las personas que consideran que lo distintivo de la retórica radica en la persuasión, no por ello deben condenarla, pues una técnica puede utilizarse para fines diversos, incluidos los moralmente buenos. Pero, señala QUINTILIANO, las personas que consideran, como él, que la retórica es el arte del bien hablar, vinculada al orador virtuoso; estas personas no tienen necesidad de justificar a la retórica de manera instrumental ${ }^{29}$. En mi opinión, esta teoría de QuINTILIANO tiene la gran ventaja de que no requiere situar a las emociones, al estilo y al carácter en un segundo plano para conservar la legitimidad moral de la retórica. No es necesario que los argumentos y una perspectiva reduccionista de la razón desnaturalicen a la apasionada y artística tradición retórica ${ }^{30}$.

Llegados a este punto podemos responder a la pregunta, ¿para QUINTILIANO la finalidad de la retórica es la persuasión? QuINTILIANO sostiene que la meta de la retórica no es persuadir, sino hablar bien (que es cosa distinta). La medicina pretende la cura de las personas enfermas, pero si no lo logra por causas no imputables al médico o la médica, aún así habrá cumplido con el fin de la medicina. El objetivo no es persuadir, sino el acto de hablar bien, pues existe una dignidad unida a ese hecho del bien hablar ${ }^{31}$. Por tanto, la retórica que QuiNTILIANO quiere enseñar no es una técnica, es decir, que su virtud no depende del uso que de ella se haga. La retórica que quiere enseñar es un modelo de vida intelectual y moral, es una retórica que no es instrumento sino virtud ${ }^{32}$. La ética de la virtud (presente en la base teórica de la retórica clásica) es una propuesta no instrumental. Esto implica que la retórica no se entiende como una relación entre medios (habilidades necesarias para persuadir) y un fin (la persuasión). Por el contrario, en la retórica de la virtud la finalidad (el bien hablar) es algo que se va haciendo mediante la praxis de las virtudes retóricas. No hay un fin que pueda entenderse al margen de una práctica de vida y, por eso, la retórica (el bien hablar) sería

26 Ibid., $\$ 2-1$.

27 Ibid., \$2-16.

28 Ibid., $\$ 2-15 ; 2-17-1,2$.

29 Ibid., $\$ 2-17-1,2$.

30 En efecto, frente al racionalismo ilustrado presente en la teoría estándar de la argumentación, las éticas de la virtud no desvinculan la razón de las emociones. Desde el punto de vista de las éticas de la virtud, para actuar correctamente es necesaria la implicación de las emociones. Esto conduce, según sostengo, a renegar de la idea de una judicatura imparcial y fría o de una abogacía técnica. Se defiende, desde la retórica de la virtud, que para emocionar es necesario que nos emocionemos primero y que desarrollemos la empatía (esta tesis es un tópico de la retórica clásica). Por eso, la empatía es imprescindible para la abogacía. Con respecto a la judicatura, la retórica de la virtud sostiene que, junto a la imparcialidad hay que situar a la virtud de la compasión como compañera inseparable.

31 Ibid., \$ 2-17-1,2.

32 Ibid., $\$ 2-17-1,2$. 
la virtud de virtudes, es decir, la praxis consistente en vivir de modo conforme con las virtudes que configuran este ideal de vida del mundo clásico. La retórica constituye un ideal político, moral y educativo, pero también constituye un ideal de realización humana y de vida óptima.

Como explica García Castillo (P. G. CAstillo, 1998) la definición del perfecto orador como vir bonus ${ }^{33}$, es uno de los temas recurrentes sobre QuINTILIANO, su gran aportación al saber retórico. La realización humana consiste en alcanzar la excelencia moral (vir bonus) por medio de la habilidad discursiva (dicendi peritus). La retórica no es solo una disciplina, sino una práctica vital, una virtud que se despliega en su vida. Según el modelo que QuiNTILIANO desarrolla en sus Instituciones oratoria, el ideal de virtud de la persona abogada está vinculado a la intelectualidad y a la ética (QUINTILIANO, 2001: $\mathbb{X}$ XII-I-I). A pesar de ser muy consciente de las características de la abogacía, como es lógico, dado que el propio QuiNTILIANO era un eminente abogado, este defendió que el motivo principal que ha de inspirar a la abogacía ideal debe ser el amor por la justicia.

Como afirma A. GEAREY (GEAREY, 2001), la persona abogada puede ser vista como héroe existencial cuya actividad le transforma a ella misma y a la sociedad. Esta visión supone apartarse de la visión de nuestros días de la persona abogada que provee un servicio a sus clientes. Podríamos denominar a dicho punto de vista «profesionalismo». GEAREY sostiene que el profesionalismo provee de una cortina de humo que oscurece las difíciles decisiones individuales que toma la persona abogada y también oculta el papel de la actividad jurídica para el cambio social. La profesión de la abogacía, vista como un trabajo técnico, continúa GEAREY ${ }^{34}$, construye apologetas del statu quo que creen aplicar objetivamente unas determinadas reglas a las disputas sociales. Esta visión ya no puede ser sostenida porque no se corresponde con el protagonismo actual de las personas abogadas. Elegir ser abogada o abogado no es simplemente elegir una profesión, sino que implica aceptar la responsabilidad de cambiar algunos aspectos de la sociedad y de la cultura. Los textos legales contienen conceptos vagos y son un lugar donde ocurren disputas ideológicas. Una aproximación retórica al derecho acepta que hay lugar para cambios e innovaciones que hagan a la sociedad más justa. Las éticas de la virtud, aunadas con un punto de vista retórico del derecho, pueden contribuir al desempeño de una labor profesional comprometida, intelectualmente rica y emocionalmente satisfecha.

\section{CONCLUSIÓN}

La noción «profesionalista» de la abogacía, muy extendida en nuestros días, concibe la abogacía como un trabajo técnico en el que los fines ya vienen determinados

33 La originalidad de este punto ha merecido estudios específicos de WinTERBOTTOM, MEADOR, BRINTON, KENNEDY. WINTERBOTTOM, «Quintilian and the vir bonus», The Journal of Roman Studies (LIV), 1964, 90-97. P. MEADOR, «Quintilian and the Good Orator», Western Speech (34), 1970, 162-169. A. BRINTON, «Quintilian, Plato and the Vir Bonus», Phylosophy and Rhetoric (16), 1983, 167-184. G. Kennedy, Quintilian, New York: Twayne Publishers, 1969.

${ }^{34}$ Ibid., 124. 
desde fuera (intereses de la clientela) y el objetivo, por tanto, consiste en persuadir a la persona juzgadora utilizando las herramientas más efectivas. La retórica sería el arte de persuadir a cualquier precio. Frente a este punto de vista, la teoría de la argumentación jurídica, reivindica una retórica racional, que es la que convencería mediante argumentos (y no mediante pasiones o imágenes) a un auditorio universal formado por personas críticas e inteligentes. En esto consiste la «Nueva Retórica» de PERELMAN.

Sin embargo, este punto de vista tiene el problema de que implica un prejuicio contra las emociones, las imágenes y lo biográfico, y se sostiene sobre una noción de la racionalidad demasiado abstracta y rupturista con la dimensión social y cultural del ser humano. Estas tensiones son particularmente notorias en el mundo del derecho, invadido hoy por una lógica instrumental. Por ello propongo el retorno a la «retórica de la virtud», un paradigma clásico que se preocupa por los elementos emocionales y estilísticos de la comunicación (además de por los argumentativos) dentro de un sistema ético que se configura como el cultivo de una serie de virtudes profesionales. Las virtudes expresan la preocupación por el lugar que ocupa el desarrollo de una profesión en el conjunto de la vida. La abogacía no se percibe como un mero trabajo técnico, sino como una vocación llena de dignidad y de retos intelectuales y morales. Considero que este punto de vista responde mejor que las éticas discursivas a la percepción de las personas abogadas sobre su trabajo y permite desarrollar las habilidades comunicativas necesarias en el derecho, haciendo que estas formen parte de un desarrollo profesional ético.

\section{BIBLIOGRAFÍA}

Alexy, R., 1989: Teoría de la argumentación jurídica (M. AtIENZA, Trad.), Madrid: Espejo CEC. Amalia, A., 2013: «Virtud y razón en el Derecho. Hacia una teoría neo-aristotélica de la argumentación jurídica», en R. GONZÁleZ DE LA Vega y G. LARigueT, Problemas de Filosofía del Derecho. Nuevas Perspectivas, Bogotá: Temis.

Amaya, A., y Hock Lai, H., 2012 (eds.): Law, Virtue and Justice, Oxford: Hart Publishing.

Aristóteles, 1970: Ética a Nicómaco (M. Araujo y J. Marías, Trans.), Madrid: Instituto de Estudios Políticos.

- 1990: Retórica (Q. Racionero, Trans.), Madrid: Gredos.

Atienza, M., 1991: Las razones del derecho. Teorías de la argumentación jurídica, Madrid: CEC.

- 2013: Curso de argumentación jurídica, Madrid: Trotta.

Castillo, P. G., 1998: «Influencias filosóficas en la definición del vir bonus de Quintiliano», en VVAA, T. Albadalejo, E. Del Río y J. CABAllero (eds.), Quintiliano: historia y cualidad de la retórica, Logroño: Instituto de Estudios Riojanos, 891-899.

Chapman, J., y GALSTON, W., 1992: Virtue, NOMOS XXXIV, New York: New York University Press.

CiCERÓN, M., 1997: La invención retórica (S. NúÑEZ, Trans.), Madrid: Gredos.

Farrelly, C., y Solum, L., 2008: Virtue Jurisprudence, Basingstoke: Palgrave MacMillan.

Gadamer, H., 1997: Verdad y método (A. Y. Agud, Trans.), Salamanca: Sígueme.

GEAREY, 2001: Law and Aesthetics, Oxford: Hart Publishing.

Habermas, J., 1981: Teoría de la acción comunicativa, Madrid: Taurus.

- 1989: «Teorías de la verdad», en Teoría de la acción comunicativa. Complementos y estudios previos, Madrid: Cátedra. 
IsOCRATES, 1928: «Antidosis», en Isocrates (G. Norlin, Trans., vol. I), Cambridge: Harvard University Press.

KANT, I., 1981: Crítica de la razón práctica (E. MiÑAnA y M. GARCía MoRENTE, Trans.), Madrid: Espasa-Calpe.

MaCInTYRE, A., 2013: Tras la virtud, Barcelona: Austral.

NussBaum, M., 1995: Justicia poética (C. GARDINI, Trans.), Barcelona: Editorial Andrés Bello.

- 2004: La fragilidad del bien, Madrid: Machado.

- 2012: Las fronteras de la justicia, Barcelona: Paidós.

Perelman, C., 1957: «Evidence et Preuve», Dialectica (11), 230-238.

- 1979: La lógica jurídica y la nueva retórica, Madrid: Civitas.

Perelman, C., y Olbrechts-Tyteca, L., 1989: Tratado de la argumentación: La nueva retórica, Madrid: Gredos.

Quintiliano, M., 2001: Sobre la formación del orador (Institutiones Oratoriae) (A. ORTEGA, Trans.), Salamanca: Universidad Pontificia de Salamanca.

SAldAÑA, J., 2007: Ética judicial. Virtudes del juzgador, México: Suprema Corte de Justicia de la Nación.

SCHOPENHAUER, A., 2002: El arte de tener razón, expuesto en 38 estratagemas (F. VOLPI, Ed., y J. AlBorés, Trans.), Madrid: Alianza.

Tovar, A., 2015: La institucionalización de la razón, Madrid: Instituto de Estudios Políticos.

VAn Eemeren, F., y GroOtendorst, R., 2004: A Systematic Theory of Argumentation. The pragma-dialectical approach, Cambridge: CUP, 1.

VEGA, L., 2003: Si de argumentar se trata, Montesinos: Ediciones de Intervención Cultural.

VIEHWEG, T., 1964: Tópica y jurisprudencia, Madrid: Taurus.

Walton, D., 1989: Informal Logic. A Handbook for Critical Argumentation, Cambridge: CUP.

YANKAH, E., 2009: «Virtue’s Domain», University of Illinois Law Review, vol. 2009, núm. 4. 